\title{
Design of a new two-dimensional proportional solenoid for miniaturized directional control pneumatic valves
}

\author{
Yeh-Sun HONG* , Dong-Hyun HA* , Myung-Ki Yeom* and Byung-Kyu Kim** \\ *Dept. of Aeronautical \& Mechanical Engineering, Hankuk Aviation University \\ Koyang-City, Kyungki-Do, Korea \\ (E-mail: yshong@hau.ac.kr) \\ **Microsystem Research Center, Korea Institute of Science \& Technology \\ Seongbuk-Ku, Soeul, Korea
}

\begin{abstract}
In this paper, a new proportional solenoid developed for a miniature 4/3-way directional control valve will be introduced. The new proportional solenoid has two-dimensional structure and a pivoting armature. The most advantageous feature of this solenoid is that its mechanical parts can be easily manufactured and assembled. The working principle and design example of the new proportional solenoid, its application to the activation of a 4/3-way directional valve and the evaluation of its control performance in position control loop will be reported.
\end{abstract}

\section{KEY WORDS}

Proportional Solenoid, Double flapper-nozzle valve, 4/3-way directional control

\begin{abstract}
Introduction
For the closed loop control of pneumatic actuators with small volumetric displacement, miniature 4/3-way directional control proportional valves having max. flow rate of less than $15 \mathrm{l} / \mathrm{min}$ are frequently required. If they are to be directly
\end{abstract}

installed on the actuators, they must be small in size. And the price should be also acceptable to promote their commercial application such as position or force control of robotic fingers $[1,2]$.

In this paper, a new proportional solenoid developed for a miniature 4/3-way directional proportional valve will be introduced. 
The conventional proportional solenoids have axis-symmetrical structure with a sliding armature whose friction force should be minimized e.g. by linear guide bearings. This makes it difficult to miniaturize them and reduce the production cost. But the new proportional solenoid presented in this paper has two-dimensional structure and a pivoting armature instead of sliding one. The most advantageous feature of this solenoid is that its mechanical parts can be manufactured inexpensively by bending thin plate and easily assembled without the armature being precisely guided.

On the other hand, the pole face of the solenoid should be properly designed, in order to determine the relationship between the armature position and the electromagnetic force pulling the armature, as depicted in the next section.

If this solenoid is combined with a double flapper nozzle valve which can be produced inexpensively by injection molding, it is possible to develop a low-priced miniature proportional 4/3-way directional control valve.

In this paper, the working principle and design example of the new proportional solenoid, its application to a 4/3-way directional valve and the evaluation of its control performance in a position control loop will be reported.

\section{Working principle of a new proportional solenoid}

Fig. 1 shows the new 2-dimensional proportional solenoid. It consists of a pole core with specially shaped pole face, a pivoting armature with extended push arm having a roller on its tip and a coil wound around the pole core. The armature is supported on the pivot edge, constrained by guide grooves, so that its motion is free from friction. The roller makes contact with a valve control element which is shown in Fig. 6.

Since the magnetic structure is two-dimensional, the max. magnetic force can be increased simply by enlarging the height.

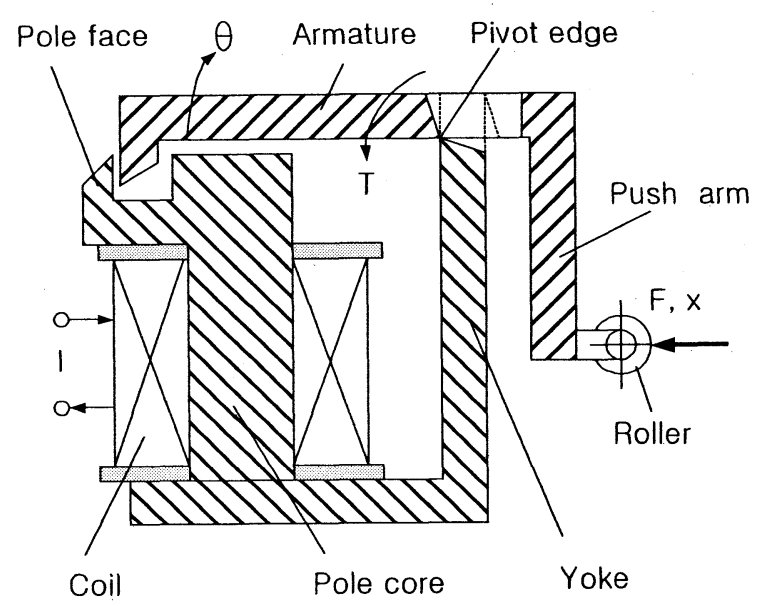

Fig. 1 Schematics of a new proportional solenoid

Similar to the conventional proportional solenoids, the relationship between the electromagnetic force pulling the armature and its rotation angle is influenced by the pole face. The design goal of this study is to make the force pushing the roller against a valve control element independent of the armature angle, where the magnetic force pulling the armature and the load force $F$ on the rolling contact should build an equilibrium with respect to the pivot edge.

In order to derive a design rule for the solenoid we need information how the electromagnetic energy stored in the air gap $W_{m}=\frac{1}{2} \phi^{2} R_{g}$ changes as the armature rotates. 
Here $\phi$ denotes the magnetic flux and the equivalent reluctance of the air gaps $R_{g}$. Using a commercial numerical analysis program (ANSOFT), the flux paths can be computed and visualized as shown in Fig. 2. Therefore, the flux paths in the air gap can be modeled as shown in Fig.3 for the derivation of $\mathrm{R}_{\mathrm{g}}$, their reluctances being expressed as $R_{i}=\int \frac{d \ell_{i}}{\mu A_{i}}$, where $\mu$ is the permeability of the air, $A_{i}$ the cross-sectional area and $\ell_{i}$ the mean path length [6].



Fig. 2 Numerically computed magnetic flux lines

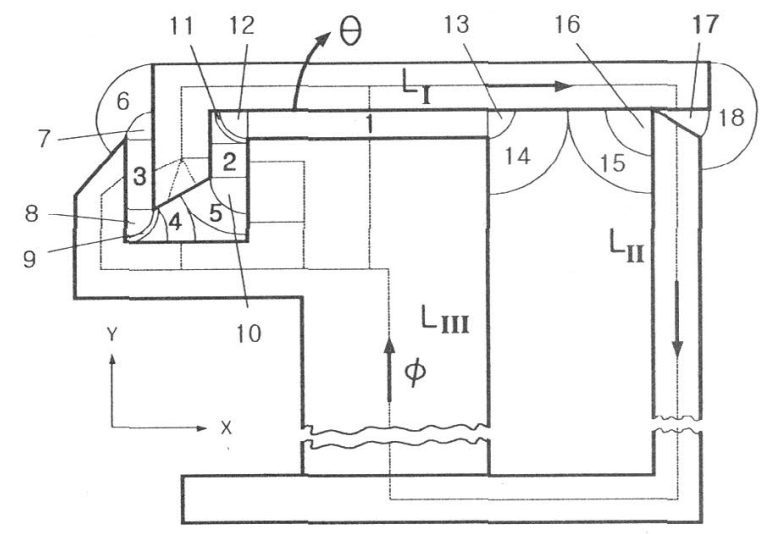

Fig 3. Approximated flux paths
Among the flux paths in the air gap, the paths 1, 2 and 3 have apparently dominant influence on the magnetic force induction, while the other flux paths represent fringing phenomenon. If the reluctances $R_{1}, R_{2}$ and $R_{3}$ are designed so that $\mathrm{W}_{\mathrm{m}}$ is kept constant during the armature rotation in the clockwise direction, the rotating moment $T$ of the armature will be also constant, since

$$
T=-\frac{d W_{m}}{d \theta}=\text { const }
$$

It is to be noted that the magnetic flux $\phi$ is determined by the magnetomotive force eq.

$$
N I=\phi R_{g}+\left(H_{I} L_{I}+H_{I I} L_{I I}+H_{I I I} L_{I I}\right)
$$

where $\mathrm{N}$ is the number of coil turns, I input current and $\mathrm{H}_{\mathrm{I}}, \mathrm{H}_{\mathrm{II}}$ and $\mathrm{H}_{\text {III }}$ the field intensity of the iron parts with the mean path length $\mathrm{L}_{\mathrm{I}}$, LII and L LII, respectively. Therefore, the magnetic saturation of the iron parts such as pole face plays also important role on keeping $\mathrm{W}_{\mathrm{m}}$ constant. Finally, if the rotating moment is constant, the pushing force on the roller tip will be also constant, while it is proportional to the input current to the coil.

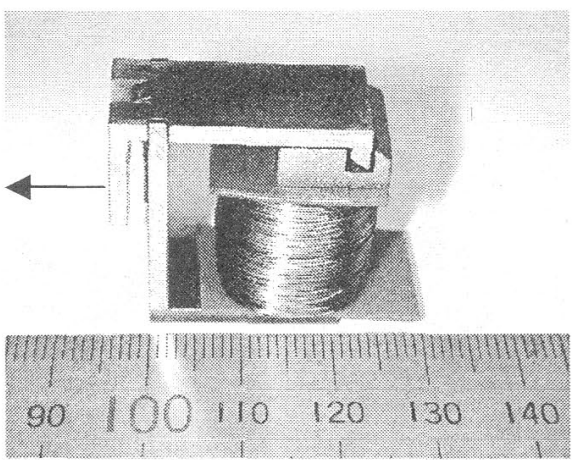

Fig. 4 Prototype of a proportional solenoid 
In this study, a prototype of the proportional solenoid was designed by a trial and error method using the numerical electromagnetic analysis program. The possibility of deriving a quantitative design rule based on the reluctance analysis is being studied and will be reported in the future.

The magnetic force-to-armature displacement curves and force-to-current curve of the prototype (see Fig. 4) is shown in Fig 5 with a $200 \mathrm{~Hz}$ dither signal applied. They indicate a hysteresis of $\pm 2.5 \%$, linearity error of less than $\pm 10 \%$ and max. force of greater than $250 \mathrm{~g}$ which is sufficient for the activation of the valve control element described in the next section.

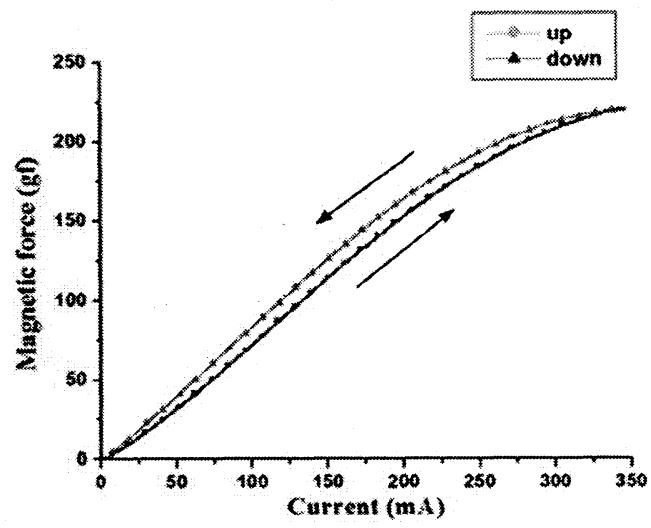

(a) Magnetic force-to-current curve

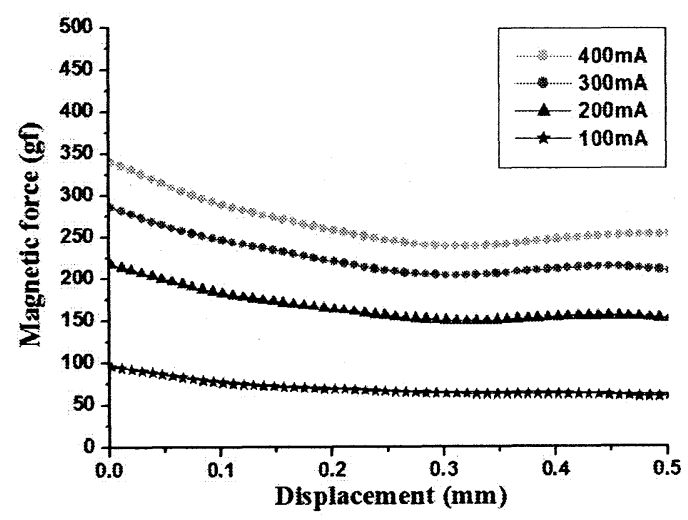

(b) Force-to-armature displacement curves

Fig. 5 Static performance of the proportional solenoid

\section{Application of a double flapper valve as 4/3-way}

\section{directional valve}

In this study, a double flapper nozzle valve was designed as 4/3-way directional valve. Fig. 6 depicts its schematics. In order to guarantee the reproducibility of the flapper nozzle valve, the valve body of a commercial product (SMC VJ114) was adopted and modified [2].

Although the flapper nozzle valves are disadvantageous in concern with the significant null leakage flow, they are simple and have good linearity between the flapper displacement and the control pressure $[3,4]$.

Table 1 shows the design specification of the double flapper nozzle valve.

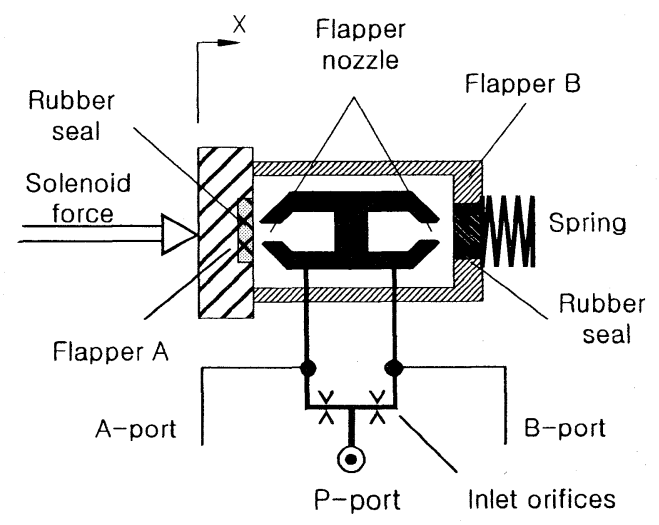

Fig. 6 Schematics of a double flapper nozzle valve

Table 1. Design specification

\begin{tabular}{|l|c|}
\hline Inlet orifice diameter & $0.4 \mathrm{~mm}$ \\
\hline Nozzle diameter & $0.7 \mathrm{~mm}$ \\
\hline Max. flapper displacement & $\pm 0.125 \mathrm{~mm}$ \\
\hline $\begin{array}{l}\text { Max. no load flow rate } \\
\text { (supply pressure }=6 \mathrm{bar} \text { ) }\end{array}$ & $7 \mathrm{~N} 1 / \mathrm{min}$ \\
\hline Spring coefficient & $215 \mathrm{~g} / \mathrm{mm}$ \\
\hline
\end{tabular}




\section{Performance of a new 4/3-way proportional directional control}

Fig. 7 illustrates the 4/3-way proportional directional control valve activated by the new proportional solenoid. The static characteristics of the valve are measured under blocked-load condition and displayed in Fig. 8. The input signal corresponds to the current input to a servo-amplifier. The curves show highly acceptable linearity errors. The flow force was negligible compared with the spring force.

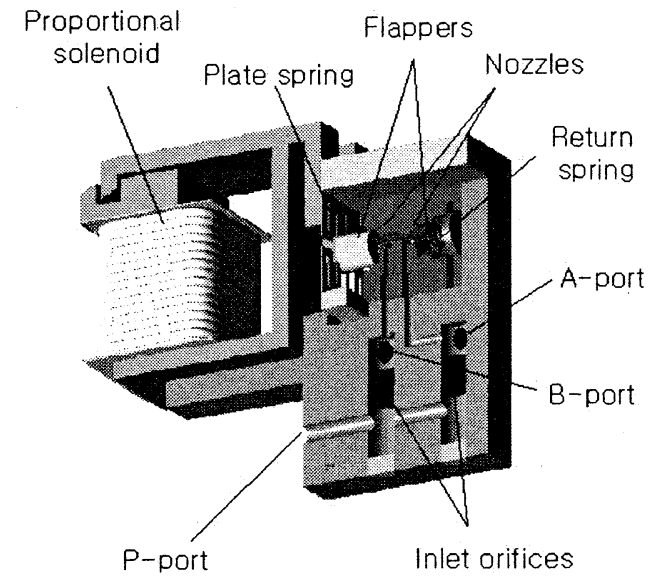

Fig. 7 4/3-way proportional directional control valve $(\mathrm{W}=45 \mathrm{~mm}, \mathrm{~L}=39 \mathrm{~mm} \& \mathrm{H}=12 \mathrm{~mm})$

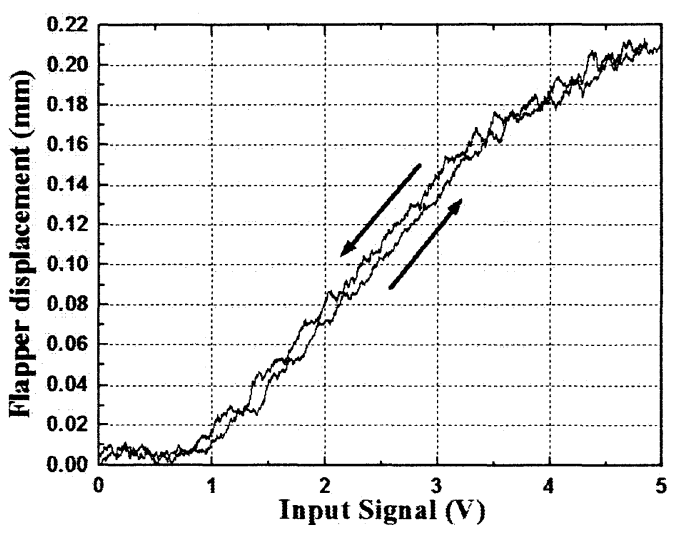

(a) Flapper displacement-to-input signal curve

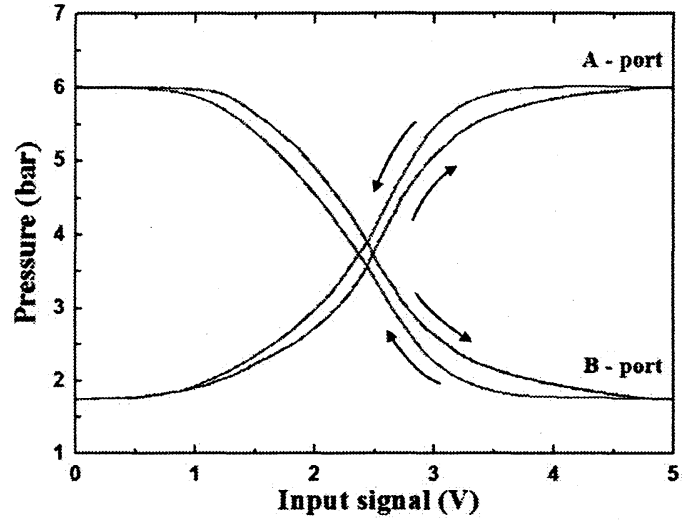

(c) Control port pressure-to-input signal curves

Fig. 8 Static characteristics of the valve (supply pressure $=6 \mathrm{bar}$ )

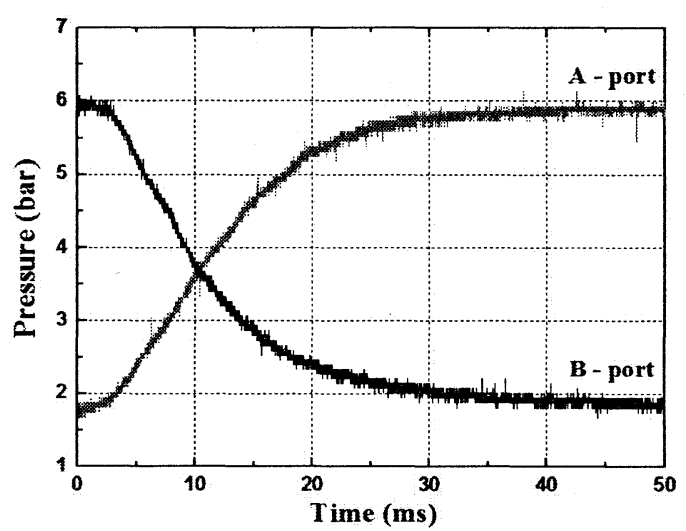

Fig. 9 Step input response of the control port pressures

The control port pressures can follow a stepwise command signal with a rising time of $23.7 \mathrm{~ms}$, which is highly dependent on the inductance and resistance of the solenoid coil, as shown in Fig. 9. Here the control ports were blocked to investigate the valve performance itself.

In order to examine the feasibility of the new valve, it was applied to the position control of a commercial pneumatic cylinder with the piston 
diameter of $16 \mathrm{~mm}$ and the stroke of $80 \mathrm{~mm}$. For this experiment a P-controller combined with lead compensator and an incremental position sensor were used. The piston could respond to a stepwise input signal with a rising time of $0.26 \mathrm{~s}$ and a steady state error of less than $0.1 \mathrm{~mm}$, as Fig. 10a indicates. When a ramp signal was applied, max. control error of $0.15 \mathrm{~mm}$ could be registered(see Fig. 10b). The results were good enough to verify the usefulness of the new valve mechanism [2,5], considering that the hysteresis error of the valve has significant influence on the control error.

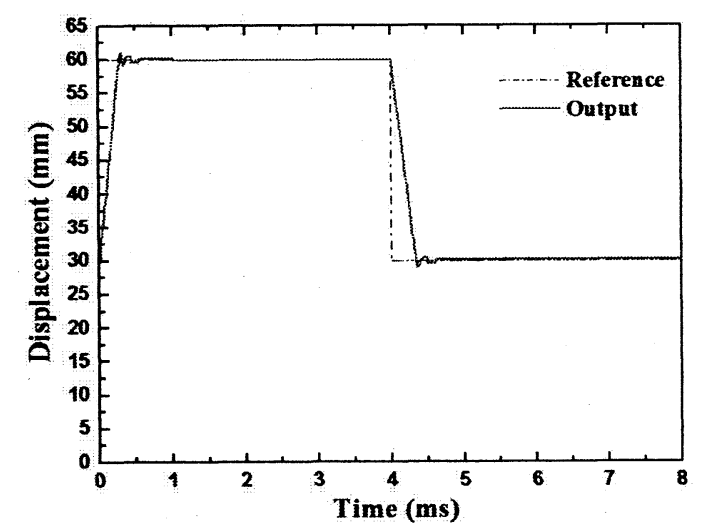

(a) Step-input response

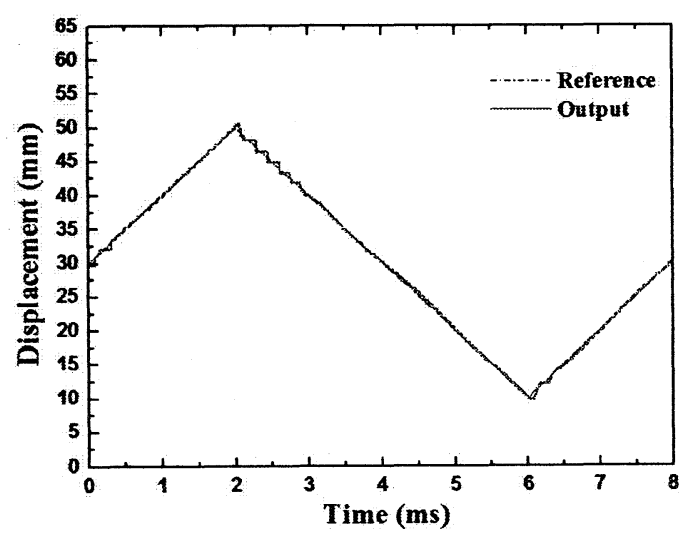

(b) Ramp-input response

Fig. 10 Step-input response of a position-controlled pneumatic cylinder
There remain certainly several remedies to improve the control performance, which was but left as future work.

\section{Review}

The proportional solenoid presented so far was made of common low carbon steel. However, its performances such as linearity error and hysteresis turned out to be on a comparable level with those of the conventional proportional solenoids. And it is highly possible to improve its performance by applying a pure iron or silicon steel. On the other hand, the design problem of the pole face should be systemized e.g. by the reluctance analysis method in order to save the trial and error approach.

\section{References}

(1) A. Czinki, Y.-S. Hong, 1997, "Design and Control of an Anthropomorphic Servopneumatic Finger Joint" Oelhydraulik and Pneumatik, March, 1997, pp. $181 \sim 184$

(2) S.B. Ryu, Y.-S. Hong, 1998, "Design and Experiment of a Miniature 4/3-way Proportional Valve for a Servo-Pneumatic Robot Hand", J. Korean Society of Precision Engineering, Vol.15, No.12, pp.142 147

(3) H. E. Merrit, 1967, Hydraulic Control Systems, John Wiley \& Sons Inc.

(4) J.F. Blackburn, G. Reethof, and J.L. Shearer, 1960, Fluid Power Control, New York, Technology Press of M.I.T. and Wiley

(5) T. Virvalo, and H. Koskinen, 1988, " ElectroPneumatic Servo System Design, " Power Int. , Vol.34, No. 402

(6) H. E. Roters, 1964, Electromagnetic Devices, New York, John Wiley \& Sons Inc. 